\title{
Environmental Visualisation as an Informing System
}

\author{
P.B. Quinn and I.D. Bishop \\ Department of Geomatics, University of Melbourne, Australia \\ quinnyb@bigipond.com idbishop@unimetb.edu.aty
}

Abstract

The aim of this research was to produce interactive, dynamic, collaborative, engaging, realistic scenes that could be used for educational or community purposes. The visualisations were based on the Macedon Ranges, a scenic area $80 \mathrm{~km}$ to the north west of Melbourne. The pedagogical foundations of good practice for on-line leaning and cooperative work were examined. Informing Science provided a framework for describing, evaluating and improving the products of the research. Conclusions from the research are that Informing Science provides an excellent framework for studying Visualisation types of Informing Systems. Editable games such as Sacrifice, Tribes2 and Unreal have promise as visualisation environments and some examples are presented.

Keywords: informing systems, environmental visualisation, computer games, pedagogy

\section{Introduction}

It is proposed that Informing Science (Cohen, 1999) provides a suitable framework to encompass the domain of interactive, multiplayer, collaborative, 3D, real-time visualisation of environments. The visualisation includes in its scope an eclectic mix of Computer Graphics, Web technologies, the physical subject of the visualisation, psychology of the participants, and the particular purpose of the visualisation. This purpose may be instructional, consultation, commercial or personal. Some of these sub-domains include the fastest developing technologies that have ever existed.

\section{Informing Science}

Cohen, E. has defined Informing Science http://inform.nu/WhatsIS.htm as a framework that:

"...Has three components: the informing environment, the delivery system, and the task-completion system."

The informing environment exists at three levels of abstraction: using an existing system; creating a new instance of that system and, at the top level, designing a new system.

The delivery system subsumes all forms of media or transmission of data, including computers. Taskcompletion system refers to the task that needs to be accomplished by the Informing System. The type of task directs the kind of information required. Cohen points out that within the definition words like 'information' can be replaced by 'services', so that the Informing Science provides a meta-cognitive layer

Material published as part of these proceedings, either on-line or in print, is copyrighted by Informing Science. Permission to make digital or paper copy of part or all of these works for personal or classroom use is granted without fee provided that the copies are not made or distributed for profit or commercial advantage AND that copies 1) bear this notice in full and 2) give the full citation on the first page. It is permissible to abstract these works so long as credit is given. To copy in all other cases or to republish or to post on a server or to redistribute to lists requires specific permission from the publisher at Publister@intormingscience.org over an otherwise fragmented but very related set of disciplines.

For the purposes of this project the Informing Science Framework will be termed the Informing System, which includes the informing environment, the delivery system, and the task-completion system. The Informing System in this paper concerns col- 
laborative and individual learning using computer-mediated visualizations of landscape.

\section{Designing Environmental Visualisations for an Informing System}

The design of an Informing System for learning should examine which of these pedagogical processes, listed below would need to be incorporated in a particular instance of the Informing Environment, Delivery System and Task-Completion System.

First however we need to recognise a caution provided by Gavriel Salomon at ED-MEDIA Montreal 2000 (http://www.aace.org/cont/edmedia/00/salomonkeynote.htm. Salomon points out the number of studies that have come up with no significant difference when you compare conventional to technologically assisted learning (that often encompass constructivist pedagogical techniques) and:

"Education is far too important to society to be wiggled by a technological tail. Let technology show us what can be done, and let educational considerations determine what will be done in actuality".

So there is a need when developing complex visualizations for learning purposes to examine pedagogical theories to ensure the production of materials that will make a difference and to find evaluation techniques that can extract significant differences from complex phenomena in order to inform decisions on how and what will be done.

Professor Sutcliffe at the City University, London echoed somewhat similar thoughts in the Report on the Virtual Reality in Education and Training conference (www.vldtk.ed.ac.uk/reports/vret98/).

".... He did note a word of caution in that there appeared to be a certain lack of work on the theoretical front particularly in the development of a suitable education and learning framework in which to advance the applied work that had been presented"

In this paper the Informing Systems Framework, derived from Informing Science are used to describe, evaluate and improve the environmental visualisations whilst using suitable pedagogy.

\section{Criteria of Development}

Suitability criteria were developed for an Informing System that uses computer-mediated, individual and collaborative Environmental Visualisation.

Sherman and Judkins (1992) have described five criteria for effective Virtual Reality implementations. Intensive: the application produces focus and concentration. Interactive: the viewer can act on the scene. Immersive: produce involvement, a feeling of being there. Illustrative: provides useful information. Intuitive: an interface to the data that is easy to understand and use. Although Virtual Reality is a term that covers a narrow suite of visualization products, Sherman and Judkins' five i's apply to many other forms of computer mediated visualizations such as 3D Games.

Listed next are the criteria by which the visualisations produced in this project were to be developed; in the context of teaching and learning in junior and middle school classrooms and in higher education.

Interactivity: empowering the viewer and giving control of significant aspects of the visualisation. The viewer needed to be able to choose a non-linear path and to go easily to areas needing closer scrutiny. The viewer should be able to vary the speed of examination and the direction of view.

Richness: Information with easy and obvious accessibility. There should be no dead ends and it should be easy to return to the beginning or a recognizable location.

Collaboration: from as simple as sharing the one computer screen; producing a group product from the information or the inspiration; sending screenshots to remote partners; watching in real-time, at least one participant interacting with the scene in some way; participants being able to interact in the scene from 
remote locations; to using e-mail, file posting, bulletin boards, shared whiteboards, video conferencing, peer to peer (p2p) techniques; to enrich, enliven and facilitate the experience.

Dynamic: objects within the scene should possess naturalistic and independent behaviours. Animals and people should move along programmed tracks or possess Artificial Intelligence (AI), similarly for vehicles or other freely moving objects. Natural features which move such as rivers, oceans, lava flows or volcanic eruptions should be animated.

Real-time: to make visualisations wherein remote participants can explore and communicate on-line.

Engaging: the visualisations should hold the interest of school students long enough to induce learning. Accessibility: the techniques should be useable by High School Teachers and hence ordinary members of the public with a good standard of education.

Realism: the visualisations though necessarily simplifications should have an obvious basis in reality.

Web enabled: it should be possible to transmit the visualisations in some form over the Internet.

Authenticity: the context of the visualisation; the work or task required from it; should be useful, bedded in reality and not trivial.

Open-Ended: the project as a whole should be future proofed by using a basic set of data- the grey scale map of the terrain, and existing maps and data of the study area, with the rapidly improving, cheaper and more accessible tools of visualisation and collaboration.

Cheapness: the programs employed should be used either during the often free trial time, during their free beta test periods, have a cheap educational or non-commercial price or be free or relatively inexpensive.

Katy Campbell's Handbook suggests 6 frameworks to create good web based instruction http://www.att.ualberta.ca/articles/1design/activel.cfm, see also Jonassen (1994) and Schank and Cleary, (1995). These are, in summary:

Multiple Realities: multiple viewpoints which demonstrate the natural complexity

Authentic Contexts: show these views as concretely and as real as possible

Case-based: leave sorting through the information to the student, leave in possibilities for their own discoveries their own analysis and synthesis

Reflective Practice: create moments or spaces for reflection

Knowledge Construction: enable the student to put the information in a context that is relevant or at least accessible to them and in a form so that they can understand the content

Kolb's Cycle of Learning requires that there should be a progression from data gathering through reflection and conceptualisation to developing solutions and implementing them.

Engagement Theory (see Kearsley at http://tip.psychology.org/create.html) requires that the work be collaborative, project based and authentic in order to entice a community or diverse group to participate.

From Learning Styles work we must make sure that information and approaches are verbal and graphical as well as serial and holistic. Informing Systems involving 3D Computer Games being naturally holistic and graphical the challenge would be to provide verbal and serial information. Time for reflection, demonstration of understanding and discourse with team members and facilitator may need to be considered depending on the task-completion system.

It may be a necessity in some Informing Systems to make sure there are effective teams. Team membership might be included in the process of joining the game, preliminary questions determining the subjects' preferred styles. 
The objectives and criteria for production of the visualizations referred to were developed using these pedagogies. The visualization using the Tribes 2 computer game was used in in a Year 9 class as a stimulus to learning. It and others more suitable for tertiary level were shown at a Geography teacher's meeting workshop where the work of the authors was displayed and participants were offered novel ways to enhance geographical learning. These instruments of learning are very exploratory: nevertheless they are worthwhile. It is difficult to discover the factors that predict success or failure of the visualizations with their different delivery systems, audiences and purposes. Informing Science provides a meta-tool to dissect the Informing System. Ideas from Complexity Theory provide insight into the evaluation and improvement of these Informing Systems.

\section{Complexity Theory and Emergent Behaviour}

The complexity of a system is determined by how complex is the model, which can predict behaviour in the system. Complex non-linear systems cannot be modeled because very small inputs can produce very divergent, unpredictable, so called emergent behaviours.

(http://www.utdallas.edu/dept/socsci/kiel.htm\#Doug Kiel) However processes can be simulated that will produce a predictable output. Thus a Mandelbrot set will produce a predictable pattern.

Doug Kiel suggests that:

"This awareness has profound impacts for organizational efforts. It also calls forth many concerns relating to the real value of creating organizational plans and mission statements and suggests instead the creation of a model of the planning process itself and subjecting this to various inputs in order to generate output scenarios." (http://www.utdallas.edu/dept/socsci/Fourth.htm\#Knowledge Management, Organizational Intelligence and Learning, and Complexity)

In the context of the research project this suggests that the best approach is a form of trial and error, recording which inputs produce successful achievement of the criteria and reproducing them as the occasion demands.

A genetic approach, the survival of the fittest producing the best learning environments; an evolution towards the fittest scenarios by take-up within the education community and perhaps by market forces, including the Stock Market, in a wider adoption process may be a way to determine developmental direction.

If one had enough computational and experimental time and resources one could invoke random numbers, string copying, and string crossover on the learning environments and with these mutations and a selection process produce better programs.

However this is a hungry approach and adaptation may have some clues on "goaling" our evolutionary development. It suggests from game theory that strategies are the structures to be examined and the operators are the rules for iterative approximation of optimal strategy (in terms of the learning environments using computer visualisations the structures would be the visualization techniques, collaborative settings and variables involving the participants; the operators being the mix of structures producing successful outcomes).

The principal performance measure would be "game-payoff" or does the learning environment "work" and do other educators adopt it?

Informing Science suggests that these structures are the Informing Environment, the Display System and the Task-Completion System and the linkages and how they link are the rules that must be adjusted to produce optimal strategy. It is very difficult to predict the behaviour of such a system but those that do give "game pay-off" can be examined for successful linkages and systems, and the information used for adaptive "goaling". 
Complexity theory encompasses the concept of emergent behaviour arising from the interaction of computers and creatures with real intelligence. It also, in part, enables us to grasp why many reductionist evaluations of constructivist learning struggle to come up with significant differences from instructivist learning, and why the problems of evaluation are complicated by the involvement of teams of people cooperating in an activity mediated by computer visualizations with varying levels of interactivity.

That teams of people display adaptiveness explains in part how various Informing Environments can produce acceptable task completion and, in part, the finding of no significant difference when computers are used as the delivery system as against textbooks- people will make sense of the data no matter what the format of the delivery system. However when the Ancient Egyptians discovered how to resurvey farm boundaries after the Nile Flood each year- a source of conflict and litigious behaviour was removed. The introduction of new technology produced effects which may be difficult to find in changes in crop yield but perhaps easier in court records. Finding the significant differences does require a holistic and naturalistic approach, as humans are so multi-dimensional and resistant to reductionism

\section{The Context of the Informing Systems}

The first author teaches in the Junior and Middle School at Kyneton Secondary College. The students in Year 7 and 8 learn in small groups called Table Small Groups (TSG), the teachers operate as a small team sharing an office, working with the same students for two years and teaching a class for more than one subject if possible. This emphasis on teamwork, in the area of computer mediated education, leads naturally to preferring methods that involve shared computer environments.

Many young people are very interested in 3D Computer Games and spend a great deal of time and effort mastering them. Using 3D Computer Games seemed to be a way of engaging students and improving their learning. That girls are not very interested in such games is partly true and ways of adapting the games, making them non-violent and more of a social experience were to be investigated. It was noted that many girls are avid users of chat rooms and it seemed reasonable that games that allowed for chat would encourage their active participation.

At least some of the visualisations needed to be based on real and local terrain; being familiar to the students, the terrain scale and other features would be understood without requiring much abstraction. The emphasis on terrain results from the desire to make topography, as an expression of other physical factorssuch as geology and geomorphology- more accessible and understandable to students.

Encouraging the students to work as a team is one of the bases of TSG. Ways of making the visualisations a team activity were to be looked at, and various collaborative techniques elucidated.

These objectives were seen to be achievable using the web and multiplayer 3D Games, though initially the technology seemed out of reach. However as the project progressed commercial computer game companies released their mission or game editors and some tutorials on their use. The potential of using these game editors as a teaching and community tool, needed to be investigated. The objective of the project then, was to use technology available to a Secondary School teacher rather than the more sophisticated apparatus at the disposal of Universities and companies, to produce visualisations that could be used for learning in schools and for group or community analysis of spatial information and decision-making. The visualisations should enable learning and discussion about the real world, incorporating current best practice in teaching and learning, including cooperative group work, projects on authentic problems, teacher as facilitator rather than instructor approaching the material in a constructivist rather than instructivist style (Papert and Harel, 1991). Close to Kyneton Secondary College the Macedon Ranges includes much that can be examined for pedagogical purposes. The terrain visualised is The Macedon Ranges, in particular Hanging Rock, an extinct volcano six million years old with a rare rock type and an unusual mode of eruption. 
Environmental Visualisation

The area is of high scenic interest with a complex geological and geomorphological history, lying $80 \mathrm{~km}$ to the northwest of Melbourne, Victoria.

\begin{tabular}{|c|c|}
\hline Web Sites & Content \\
\hline a-tractor.com & site of the MMOG tractor game \\
\hline bhbug.simplenet.com/art/2historia.htmI & A history of Computer Graphics \\
\hline hem.passagen.se/ulkis/onlineworlds/screenshotindex.htm| & list of Massively Multiplayer Games \\
\hline |1iftoff.msfc.nasa.gov/realtime/JTrack/3d/JTrack3D.htm| & web site for visualising satellite positions \\
\hline Sites.netscape.net/mcyrhul/WIMPSI.htm| & History of Computer Programming \\
\hline web.jet.es/leobueno/leo_flight_sim.htm & a flight simulator for handheld computers \\
\hline WWW.3Dcafe.com & free models and tutorials on 3D \\
\hline Www.aace.org/cont/edmedia/00/salomonkeynote.htm & Gavriel Salomon at EdMedia 2000 \\
\hline WWW.ActiveWorlds.com & VRML viewer \\
\hline Www.arch.usyd.edu.au & University of Sydney Architecture site \\
\hline WWw.atl.ualberta.ca/articles/1design/activel.cfm & $\begin{array}{l}\text { Campbell's } 6 \text { frameworks for web based } \\
\text { instruction }\end{array}$ \\
\hline WwW.Blaxxun.com & VRML viewer \\
\hline WwW.caida.org/tools/visualization/mapnet/ & mapping the location of websites on line \\
\hline Www.casa.ucl.ac.uk & Centre for Advanced Spatial Analysis \\
\hline $\begin{array}{l}\text { Www.crcg.edu/events/siggraph/sig00/theresa/overview- } \\
\text { netgraf3.htm| }\end{array}$ & Internetworked 3D Graphics \\
\hline Www.cybergeography.org/atlas/more_1sp_maps.htm| & Internet traffic mapping \\
\hline www.Dynamix.com & Tribes 2 company \\
\hline Www.endeavors.com/news/1paq.htm & Ipaq handheld computer and mapping \\
\hline WWW.Endtech.com & MagiExpress p2p program. \\
\hline WWw.e-onsoftware.com & Vue D'Esprit program \\
\hline WwW.Equill.com & Mark-up \\
\hline Www.fathammer.com/x-forge.html & game program for handheld computers \\
\hline www.thfurtwangen.de/ dersch/ & panorama program \\
\hline WWw.FPSweb.cjb.net & modification of Tribes 2 \\
\hline WWW.garagegames.com & Torque Game Engine Web Site. \\
\hline WwW.Groove.com & Groove $\mathrm{p} 2 \mathrm{p}$ software \\
\hline www.hq.nasa.gov/office/pao/History/computers/Source9.html & history of computers \\
\hline WWW.Icq.com & email, SMS, paging and file sharing \\
\hline WWW.1mass.co.uk/navigator.shtml & real-time mobile computing using GIS \\
\hline www.Intelliwhere.com. & GIS that can speak \\
\hline WWW.juna.dmi.tut.fi/gpsdemo/demo-applet/main2.html & gps tracked object on 3D terrain model \\
\hline Www.Kaon.com & 3D models for collaboration on a website \\
\hline WWW.microtopo.com, & 3DEM \\
\hline WwW.Morfit.com & of MorfitWorld tools \\
\hline
\end{tabular}


Quinn \& Bishop

\begin{tabular}{|l|l|}
\hline Www.neocron.com & Massively Multiplayer Game \\
\hline www.newircusers.com/ircintro.html & An Introduction to IRC Networks \\
\hline Www.pandromeda.com & render whole planets \\
\hline Www.Kealitywave.com & tools for constructing 3D models on line \\
\hline Www.Sierra.com & Tribes 2 game \\
\hline Www.tadpole.com/car/1ndex.htm & handheld mobile mapping using p2p \\
\hline www.trinityofdarkness.com & Massively Multiplayer Game Engine \\
\hline www.utdallas.edu/dept/socsci/kiel.htm\#Doug Kiel & Complexity Theory \\
\hline Www.vldtk.ed.ac.uk/reports/vret98/ & VRET'98 \\
\hline Www.Vtp.org & Virtual Terrain Project \\
\hline Www.Webscrivener.com & mark up tools \\
\hline \multicolumn{2}{|c|}{ Table 1. Simulators, games and other sites pertinent to the work. } \\
\hline
\end{tabular}

\section{The Informing Systems}

\section{Display System}

A very large number of software products designed for both serious activities and fun now include some ability to visually simulate the natural environment. Table 1 lists some of the web-site which describe such products. The quality of the simulation depends first on whether real-time movement or sophisticated rendering is the first priority. When real-time movement is required the quality then depends on the speed of the graphics card being used in the computer. The display system for this work included the au-

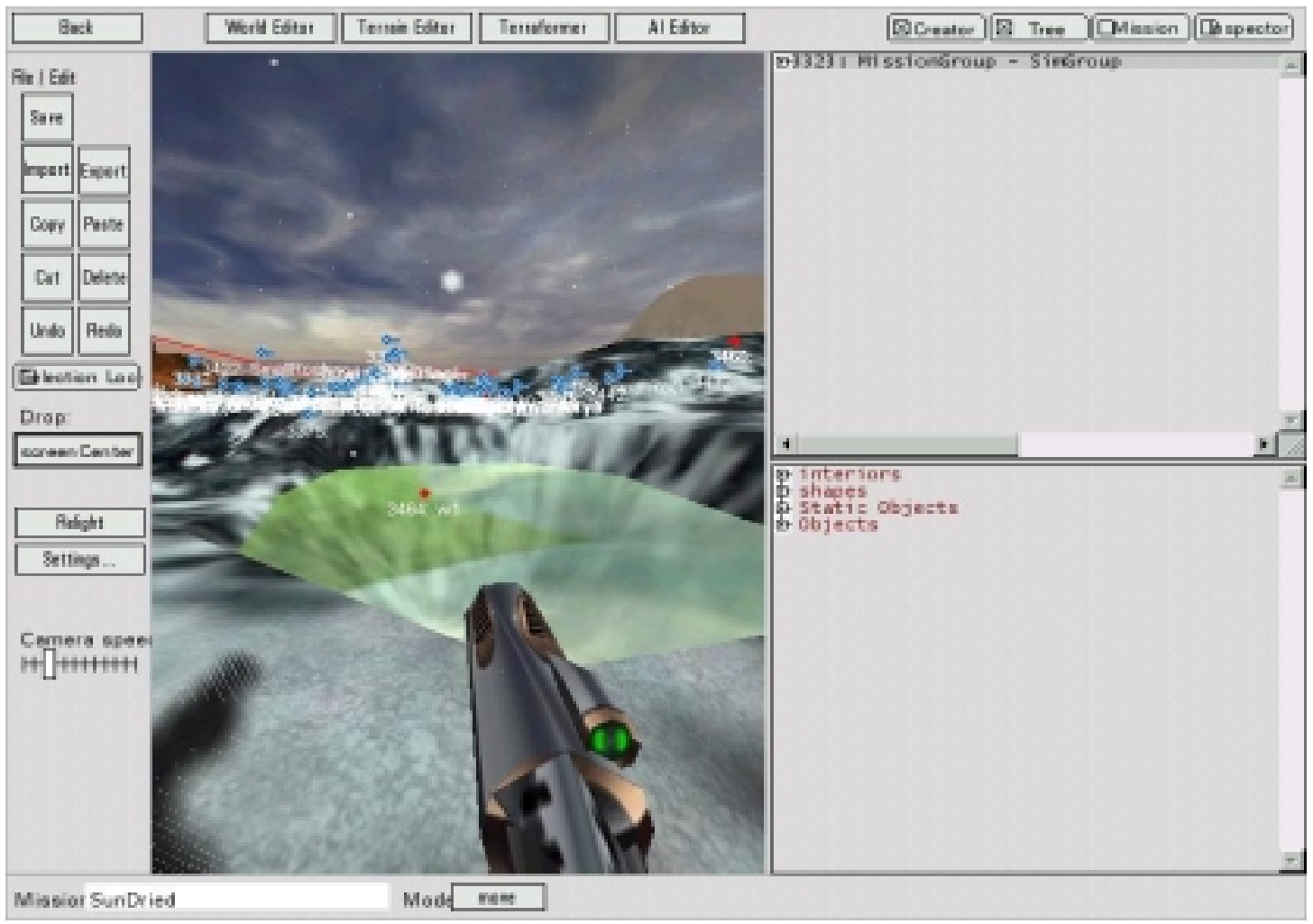

Figure 1. The Mission Editor in Tribes 2. 
thor's PIII computer with 128Mb Ram and an nVidia TNT2 3D Graphics card showing the 3D game. This machine also produced the printed screenshots below. The text containing information on toxic waste disposal (see below) was also part of the Informing Environment's display System. The classroom whiteboard also had a role to play.

\section{Visualisation Environment and Task-Completion System}

Tribes 2 was used as the Visualisation Environment. In early 2001, Tribes 2 was released and a new era of on-line gaming began. The game features extensive outdoor scenes as well as detailed indoors. The player models are elaborate and can be animated to show gestures to the other players. There has been a conscious effort to reward good team play in the scoring of the game. Cooperation by repairing generators and giving health to other players is rewarded.

The game features the best Mission Editor available at this time. It is largely unsupported and requires close studying of modelling and map- making forums. The forums are of variable quality. Dynamix, the company that produced the game have supplied some tutorials and files. The game itself, published and distributed by Sierra, is updated when you log into the main T2 game server. The Mission Editor is opened by running a game off-line in Solo or LAN mode then pressing the $\sim$ key. This opens the console. In the text section that appears you type "editor.open();" without the speech marks and press enter. Pressing $\sim$ will close the text area and the mission editor can be seen clearly (Figure 1). In Figure 1 there is an example of a lake. The water feature is complicated to add. It requires extraction of the details of the Game files on the CD by changing the proprietary file ending to .zip and then open using an unzip facil-

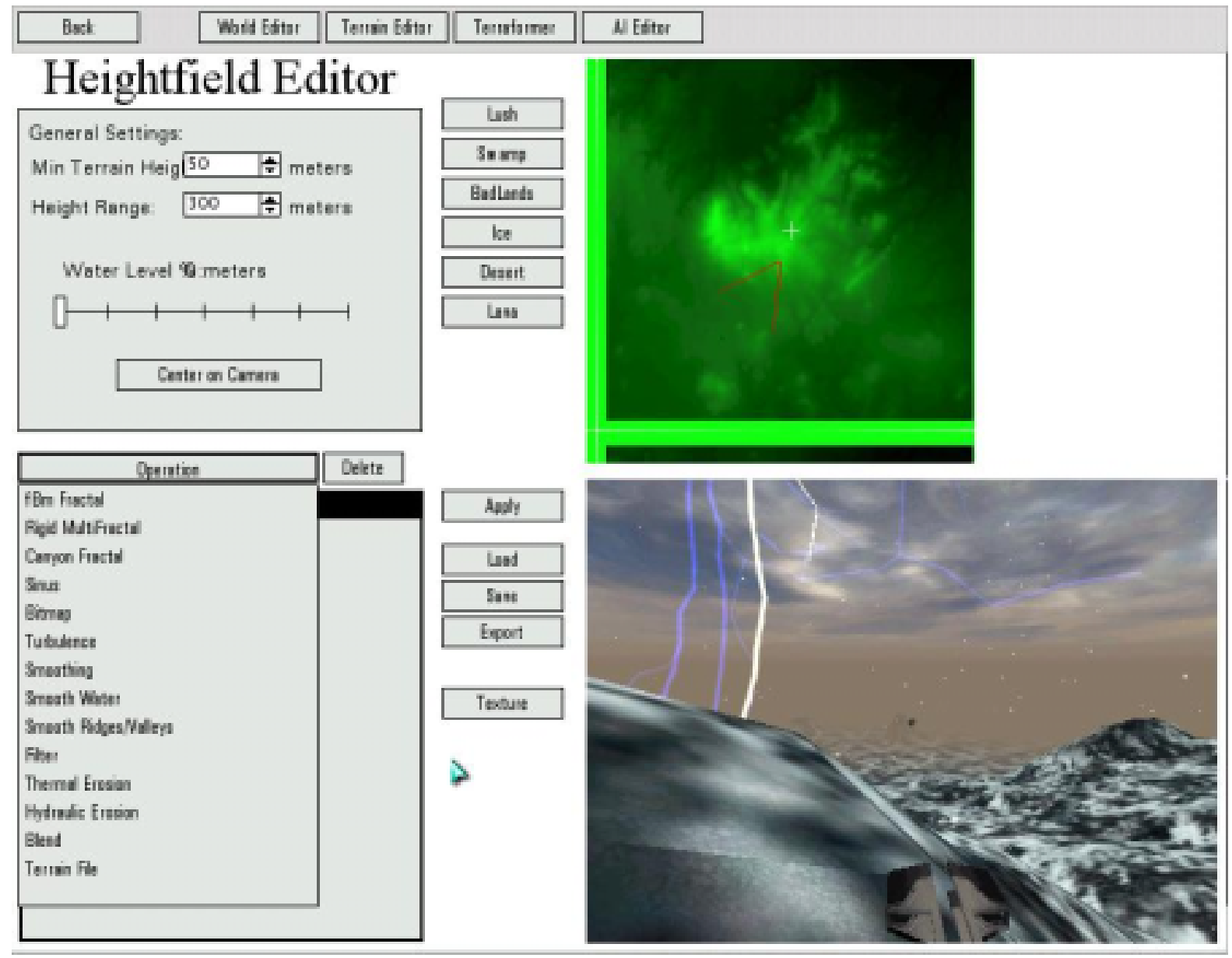

Figure 2. The Heightfield Editor showing smoking Hanging Rock in the distance. 
ity. It was necessary to find an appropriate environment map for the water surface (otherwise you have a lake with white un-textured water). The water has animating oceanic swells-which it would be good to be able to turn off as a small lake should have had only small waves.

In the Mission Editor (Figure 1), can be seen the Terraformer button. In this you can bring in .png format greyscale maps (the instructions on the Dynamix web page says bitmaps- but they do not work). In Figure 2 the Mt Macedon scene is being edited: the game and AI controlled bots continue to run and lightning can still strike your character. Various settings can be used to create fractal terrain as well.

The ability to bring in your own greyscale terrain, which you can produce in other programs, is an excellent facility.

The Macedon Ranges Terrain was created and a lake with a green algae surface environment map was placed next to a smoking chimney. This represented a High Temperature Toxic Waste Disposal Facility. To make it more controversial it was placed next to Hanging Rock, a local scenic attraction. Near Hanging Rock were placed some vehicles. The player appeared to the south of the Macedon Ranges at the beginning of the game and in running to Hanging Rock to see the Waste Facility and to try the vehicles, most of the terrain would be examined. The Mission Centre with its otherworld architecture had to be placed in the mission scene for it to work properly. The students did not find it disconcerting.

In Figure 3 a hypothetical Toxic Waste facility has been added to the landscape near Hanging Rock. Students in a year 9 class at Kyneton Secondary College were asked to produce a publicity poster for or against the facility: in the simple terms of environment versus jobs. They could use the screenshots for their poster. One group decided they were no good for promoting jobs at the facility and produced their

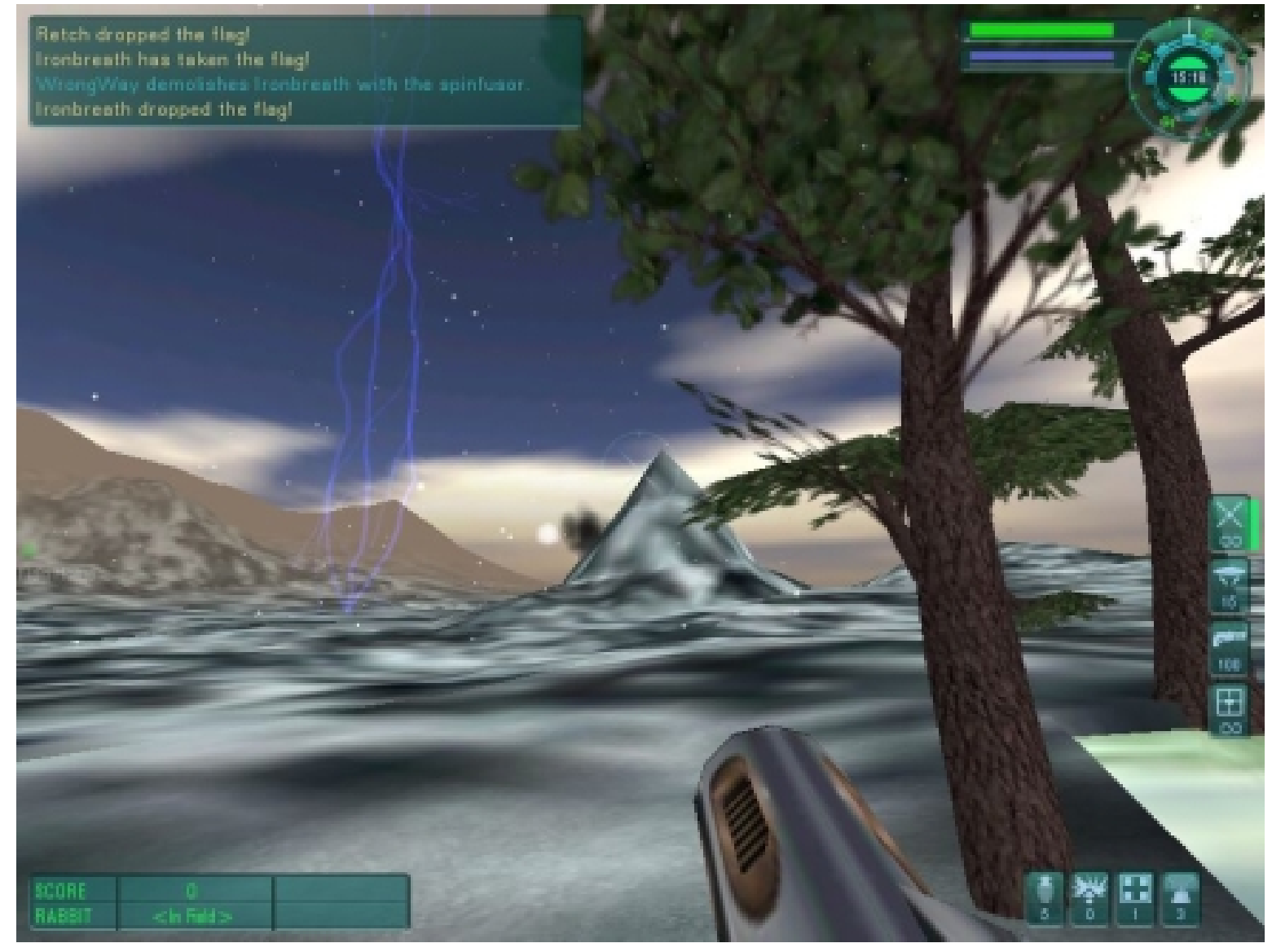

Figure 3. View from a Hypothetical Toxic Waste Facility near Hanging Rock. 
own screenshots from their own games e.g. Dukes Nukem. Subsequent to the exercise the author discovered how to lay down the weapons - "ctrl w". Tribes2 has an excellent terrain making facility and it produces an attractive landscape, which can be interacted with, in real time, over the web. It is relatively easy to add vehicles and spawn points (where the avatar appears at the beginning of the game). It is an engaging product and students will play with it for a long time. There are problems adding user-generated models, and the overlays are obscured by tiled textures.

The game was enjoyed but it took two periods for each team to have a fly around. The girls participated and enjoyed this as well as the boys. The enjoyment came partly from the novelty of doing something different and also from the entertainment aspects of the game environment including being able to move over the terrain and also shoot at various objects and splash in the toxic pond.

The follow up activity was done poorly basically because it was a group poster persuading the public to their point of view about the toxic waste disposal facility and the students seemed uninspired by the use of that medium and also perhaps because of the implausibility of a plant next to a local scenic attraction.

The printed information from a class set text was local in its information but dull in contrast to the 3D Game. The students seemed inspired by the fly around but in some way cheated by the method of presentation they were restricted to. It may have been better if they had access to a computer lab to produce their report.

However one of the aims of the Small Table Groups program in Year 7 and 8 that these students had been through, has been to train the students to cooperate and research and report in groups. The Games Project was carried out in quite large groups of 6 students. Tasks were generally divided according to the students talents- such that the computer expert did the Duke Nukem visualization, the researcher got the info from the text and the others did the writing and drawing for the poster. Whilst the teacher was engaged in wiring up the computer and setting up the display they were cooperative and helpful.

The visualisation itself was accepted as a model of the Toxic Waste Site without any quibbles as to its visual reality. Indeed the changes to the scene requested by the students showed that they perceived it as being persuasive and in need of careful manipulation from the point of view of your group. This is also an important insight to gain for the students that 3D Visualisations are as subject to propagandist manipulation as any media.

The terrain itself was perceived to be a good representation of the local landscape to the extent that students were trying to work out where their homes were. Overall it was a valuable exercise in designing and making a Visualisation System for the purposes of completing a task, in a team situation and using Tribes 2 and the Macedon Range Terrain as part of the Visualisation Environment.

It was almost surprising that it could be completed despite the complexity of the system. Great results may be possible from these students if the "neural network" of the Informing System could be "goaled" adaptively. In other words it needs to be tried again this time with a smaller, more do-able task and a less complicated set-up.

The Visualisation System was valid in terms of being a realistic version of the local terrain in that students could work out where they were from the local landmarks. To them Mt Macedon was in a correct relationship in scale and distance to Hanging Rock. In addition when the instruction to head for the top of Mt Macedon was given they knew where to go. They were told the Toxic facility was next to Hanging Rock and they had no difficulty finding it. A further incentive to find it was the presence of a plane allowing for a high speed flight around the district- including being able to attack a few exotic looking target buildings. 


\section{D Webmaker}

Morfit.com has released its web version of the MorfitWorld editor. It is called 3D Webmaker and available through www.Northdragon.com. Scenes constructed in MorfitWorld are exported to a web format based on Javascript and Active-X. The scene (Figure 4) shows the terrain of the Macedon Ranges with the geology overlain. The geology overlay was made by making a screenshot of the geology in the MapInfo viewer provided on the free CD of the Department of Natural Resources and Environment's Geological Survey of the Melbourne area. A key to the colours was made from an old map of the author's and pasted beneath the geology map in the right hand window of the web page.

Information on the geology of the region can be accessed by clicking in the lower window on a hyperlink to a Word document containing extensive information on the geology and geomorphology of the region. Screenshots of selected locations are used to illustrate the text- an example of an Informing System using a 3D Informing Environment to produce illustrations for a static web page or text.

\section{Validities of Visualisation Systems}

Consideration of the validity of Visualisation Systems for decision-making, learning and other tasks is appropriate. Are these simulations of landscape and other $3 \mathrm{~d}$ features useful enough to enable people to make real world decisions and have a sense of true experience? In Bishop and Hull (1991) three studies are cited (Bishop and Leahy, 1989; Orland, 1987; Vining and Orland, 1989) these all give confidence that computer mediated simulations are valid. A moderately strong relationship between photographs of a scene and computer-simulated scenes was shown (Bishop and Leahy, 1989).

Subjects' evaluations of the realism of a simulated day and night urban environment compared to a real

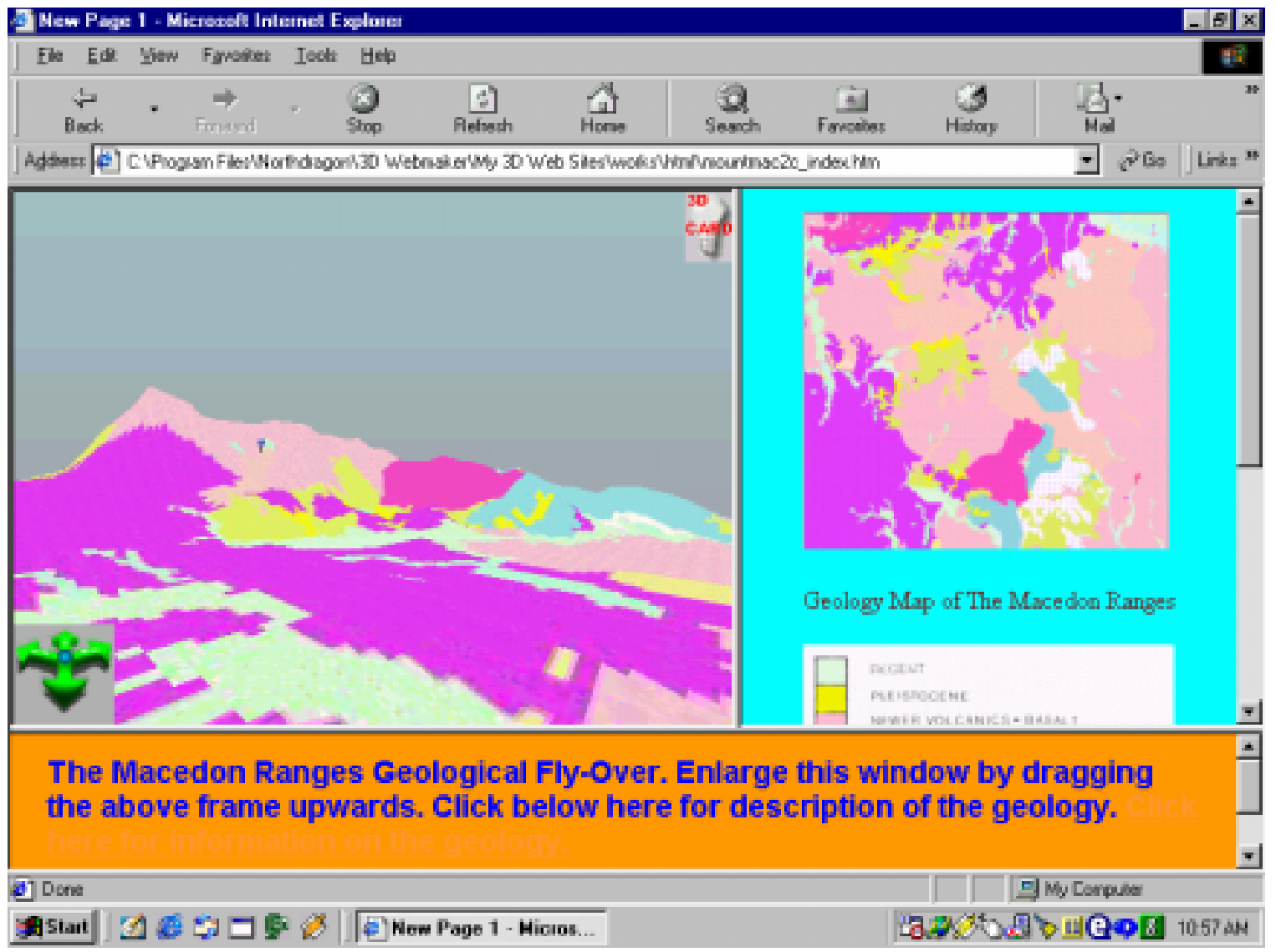

Figure 4. The Macedon Ranges Geological Flyover. 
walk through of the study area (Rohrmann, B. and Bishop, I.D., in press) showed that the computer simulation induced a less positive perception of the scene and procured a less detailed memory of it. The night and day scenes produced similar reactions. The Visualisation Environment was an animation along a defined walk and made with Alias Wavefront's Advanced Visualiser. The Delivery System was a video on a television monitor. Conclusions based on the subjects' responses were that the simulation was accepted as reasonably valid and improvements could be made by increasing the realism of the colours and of the vegetation. It is pointed out that the respondents required that the vegetation be only identifiable as such and not hyper-realistic. This is gratifying as interactive dynamic games like Tribes 2 and Sacrifice can afford few detailed 3D trees at present, trembling leaves in the soughing breeze await the near future.

Empowering members of the general public on a broad scale to share and decide on aspects of an environment can be achieved using relatively inexpensive and simply produced 3D Visualisations that can be placed on a web page in a suitable viewer that can be downloaded. Bishop (1994) argues that the nonscientific public need: 'Abstraction minimised, information content maximised and the whole package digestible and non-threatening... and this calls for an interactive approach'

In the Visualisation Systems based on Tribes 2 and those based on 3D Webmaker a high level of interactivity of various kinds is provided that are in general aesthetically pleasing. They provide a deal of information on the terrain in the Tribes 2 setting. The '3D Geology of the Macedon Ranges' is in an interactive, visual, 3D format, which is perhaps more digestible than a contour map overlain with geology symbols and colours. It may thus satisfy some of Bishop's criteria (1994).

Evaluation of a complex system requires the use of evaluation techniques that are holistic. In addition usability, or formative evaluations can be used while an Informing System is at the exploratory stage and in early development cycles. Naturalistic evaluation is a technique that leads to the production of case studies and a means of "projection of next steps". These evaluation techniques seem to be devoted to finding out how to improve what we are doing and to place less emphasis on attempting to untie the Gordian knot. Adaptive goaling, much like auto-tuning of an adaptive neural network moves the system towards improvement. People engaged in a task-completion activity will tune the systems to produce the required output using scant information but lots of intuition, thus pushing many inadequate informing systems to a successful conclusion regardless. However despite the overall systems being complex with the possibilities of emergent behaviours the task to be completed can be evaluated in a reductionist statistical manner, as a measure of the worth of the system but not as an explanatory tool. Though statistical correlations cannot be presumed to show cause and effect in any case.

The Visualisation Environment and the Display System need to be carefully considered in terms of the participants and their range of behaviours as well as the data to be engaged with and its best setting and the approach to it. The Task-completion System needs to be designed to provide the opportunity to exercise the higher levels of thinking and to produce outcomes that demonstrate deep understanding of an authentic i.e. 'important' or 'worthwhile' simulation.

This research has investigated and trialled some techniques for the provision of interactivity and improved engagement with the learning or exploration of data and terrain, in an attempt to address the comments of Bishop, Salomon and Sims above and to find valid purposes and designs for the visualisations.

\section{Future Directions: Fulfilling More of the Criteria}

In order to develop ideas on future directions for this work the final products of this research project needed to be examined against the original criteria of the thesis. The criteria were that the visualisations should be: interactive; rich in information; collaborative; real-time; engaging; accessible; realistic; webbased; authentic; open-ended and cheap. 
The '3D Geology of the Macedon Ranges' (Figure 4) as it stands is realistic, web-based, information rich, accessible. It is useful in authentic problem solving, it is open-ended- the framework can use various maps and data, it is interactive, if the model is produced in the trial period it is free and US\$49 for a noncommercial licence and US $\$ 400$ for the full licence afterwards. It can be made to be collaborative (at least screenshots) using $\mathrm{p} 2 \mathrm{p}$ frameworks and it is engaging. The scene is dynamic in that a vehicle is driving around the Ranges while the player is viewing (the vehicle is very small- but approximately to scale and almost undetectable).

It still needs several criteria to be fully implemented and in particular collaboration within the scene, it should be relatively easy to place a text chat window in the lower window. Northdragon.com have a demo of a multiplayer version on their web site, which already has a chat feature implemented and this functionality should be relatively easy to add to the 3D Geology of the Macedon Ranges.

3D Games like Tribes 2 and the forthcoming Unreal 2 provide platforms within which many people can interact in real time. 3d Models can be imported and laid onto a very large outdoor terrain that can be based on real locations. Editable avatars provide realistic characters that represent the participants. Animated gestures and real time chat using the chat facilities or microphone connection create an engaging environment. Sacrifice another commercial computer game is net workable in a recent update. Its dynamic terrain features contained within its "spells" demonstrate what can be done with its Game Engine.

The Informing System based on Tribes 2 was an initial effort in this direction. It is collaborative, on-line in real-time, engaging, interactive and realistic. Its limitation being the lack of a facility to overlay images onto the terrain, except as texture tiling. Though it should be possible to break up a large image into tiles that could then be overlain.

A viewing platform based on a Game Engine similar to Tribes2 or Unreal2 (to be released in early 2002) would provide functionality and engagement well beyond that available in the ' $3 \mathrm{D}$ Geology of the Macedon Ranges' Informing System. However these games do require a CD and large programs need to be installed on the computer. 3D Geology of the Macedon Ranges and Informing Systems like it, based on a relatively small download of an Active X program have the advantage of being free to download and cheapness and ease of production. However the future would seem to be with games such as Unreal 2 and Tribes clones. They exploit the latest improvements in 3D Graphics cards and push the Internet to the limits of performance. The commercial imperative exploits the latest advances in computer graphics. It would seem that the marketplace is 'adaptively goaling' 3D Games in an evolutionary process towards something that is as yet unfathomable but which will be profitable. The challenge is to add functionality that would also make them useful.

\section{References}

Bishop, I. D. (1994). The role of visual realism in communicating and understanding spatial change and process. In H. M. Hearnshaw \& D. J. Unwin (Eds.), Visualization in Geographic Information Systems . Chichester: John Wiley.

Bishop, I.D. and Hull, R.B. (1991): Integrating technologies for visual resource management. Journal of Environmental Management, 32, 295-312.

Bishop, I.D. and Leahy, P.N.A. (1989) Assessing the Visual Impact of Development Proposals: The Validity of Computer Simulations. Landscape Journal, 8 92-100.

Cohen, E. (1999) Reconceptualizing Information Systems as a Field of the Transdiscipline Informing Science: From Ugly Duckling to Swan. Journal of Computing and Information Technology. 7, 213-219.

Jonassen, D.H. (1994). Thinking technology. Educational Technology, April, 34-35.

Orland, B. (1987). Video-imaging in Design. Landscape Australia, No.1, 46-49.

Papert, S.and Harel, I. (1991) Constructionism. Norwood, NJ, Ablex Publishing Corporation. 
Environmental Visualisation

Rohrman, B. and Bishop, I.D. (in press). Subjective responses to simulated and real environments: A comparison. Journal of Environmental Psychology.

Schank, R.C., \& Cleary, C. (1995). Engines for education. Hillsdale, NJ: Lawrence Eelbaum Associates.

Sherman, B. and Judkins, P. (1992) Glimpses of Heaven, Visions of Hell - Virtual Reality and its Implications. London, Hodder and Stoughton.

Vining, J. and Orland, B. (1989) The video advantage: a comparison of two environmental representation techniques. Journal of Environmental Management, 29, 275-283.

\section{Biography}

Brian Quinn (B.Sc (Hons) Dip.Ed.) has been teaching in High Schools in Victoria, Australia since 1973. Presently completing a M.App.Sc in the Department of Geomatics at University of Melbourne working on the areas which are the subject of this paper. He also breeds plants, especially grasses and markets them.

Ian Bishop (B.Sc.(Hons) M.Sc. PhD.) is an Associate Professor in the Department of Geomatics and also the Faculty of Architecture, Building and Planning at the University of Melbourne. His research is in the broad area of geographic information systems and environmental visualisation applied to landscape analysis, perception and planning. 